\title{
Study on Meso-scale Grinding Surface Roughness and Sub-surface Quality of High Volume Fraction SiCp/Al2024 composites
}

\section{Guangyan Guo}

Liaoning University of Technology

Qi Gao ( $\nabla$ qqonline@163.com )

Liaoning University of Technology

Quanzhao Wang

Chinese Academy of Sciences

Yuanhe Hu

Liaoning University of Technology

\section{Research Article}

Keywords: SiCp/Al2024 composites, Two-dimensional simulation model, SiC particles, Surface roughness, Sub-surface quality

Posted Date: July 28th, 2021

DOl: https://doi.org/10.21203/rs.3.rs-742295/v1

License: (c) (i) This work is licensed under a Creative Commons Attribution 4.0 International License. Read Full License 


\title{
Study on Meso-scale Grinding Surface Roughness and Sub-surface Quality of High Volume Fraction SiCp/Al2024 composites
}

\author{
Guangyan Guo ${ }^{1}$. Qi Gao ${ }^{1}$. Quanzhao Wang ${ }^{2}$. and Yuanhe $\mathrm{Hu}^{1}$
}

Received:

/Accepted:

\begin{abstract}
In order to improve the surface grinding quality of high volume fraction aluminum matrix composites, the cutting tool models with different rake angles are established, the grinding process is simulated, and the material removal mechanism and the broken state of SiC particles are obtained. Through single factor experiment, the $60 \%$ volume fraction $\mathrm{SiCp} / \mathrm{A} 12024$ composites are ground by diamond grinding rod with $3 \mathrm{~mm}$ diameter, the surface roughness $(R a)$ is measured, and the surface and sub-surface quality of $\mathrm{SiCp} / \mathrm{A} 12024$ composites with meso-scale grinding is investigated. Meanwhile, the influence mechanism of grinding depth $\left(a_{\mathrm{p}}\right)$ on surface quality is put forward, and the influence of different grinding depth on the fragmentation of $\mathrm{SiC}$ particles in sub-surface layer is discussed, which verifies the correctness of grinding simulation. The relevant research and theoretical model are of great significance to the study of grinding properties of composite materials.
\end{abstract}

Key words: SiCp/Al2024 composites. Two-dimensional simulation model. SiC particles. Surface roughness. Sub-surface quality

\section{Introduction}

$\mathrm{SiCp} / \mathrm{Al}$ composites are metal matrix composites included with $\mathrm{SiC}$ particles and aluminum matrix. Due to its high heat conductivity coefficient, low thermal expansion coefficient, high strength, low density and other excellent characteristics [1], it has gradually become the focus of scholars. The material is widely used in including aerospace, precision instruments, optical and mechanical components and inertial devices, and so on [2-5]. In recent years, some scholars have

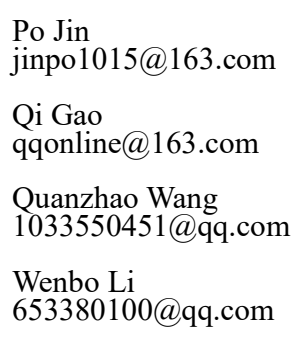

1. School of Mechanical Engineering and Automation, Liaoning University of Technology, Jinzhou, 121001, China.

2. Institute of Metal Research, Chinese Academy of Science, 110016 studied the properties of metal matrix composite by means of grinding, so as to be better applied in practice.

A large number of scholars have explored the grinding mechanism of composite materials through grinding simulation. Zheng et al. [9] simulated the formation mechanism of surface defects in ultrasonic grinding of $\mathrm{SiCp} / \mathrm{Al}$ composites. The results showed that the removal forms of $\mathrm{SiC}$ particles mainly include rolling in, breaking and pulling out. Zhang et al. [10] used the finite element analysis software (Abaqus) to simulate the process of grinding $\mathrm{SiCp} / \mathrm{Al}$ composites with single Diamond Grits, and analyzed the influence of grinding speed and grinding depth on grinding force, the surface morphology and residual stress distribution of the workpiece after grinding were studied, which provided a reference for optimizing the processing parameters of $\mathrm{SiCp} / \mathrm{Al}$ composites ground by diamond grinding wheel. Ma et al. [11] based on the Abaqus, the Johnson-Cook constitutive model was used to simulate the chip shape, chip shear angle and grinding force in high speed grinding of Ti6Al4V with different abrasive negative rake angle. Wang et al. [12] set up a two-dimensional finite 
element model consisting of hard silicon carbide particles and soft aluminum matrix to study the milling process of $\mathrm{SiCp} / \mathrm{Al}$ composites. The simulation results showed that the rotation, stretching, cracking, micro-fracture and cutting of sic are the main mechanisms of defect formation. The simulated machined surface morphology was compared with the milling surface profile, and a good correlation was obtained.

More and more scholars put forward the grinding mechanism of composite materials through the experimental method. Yu et al. [13] studied the form of grinding removal of high volume fraction $\mathrm{SiCp} / \mathrm{Al}$ composites, analyzed the morphology and types of grinding surface defects and debris of SiCp/Al composites by SEM observation, and put forward its formation mechanism, a three-dimensional nonlinear finite element model of the grinding conditions in the plastic region of $\mathrm{SiCp} / \mathrm{Al}$ Composites was established, and the effects of the radius and the depth of the blunt ball on the brittle-plastic transition of $\mathrm{SiC}$ particles in the hard reinforced phase of the composites were investigated. Guan et al. [14] used ELID grinding technology to conduct precision grinding experiments on $40 \%$ volume fraction $\mathrm{SiCp} / \mathrm{Al}$ composites, studied the formation mechanism of machined surface, analyzed several typical grinding surface defects, and the grinding characteristics and removal mechanism of $\mathrm{SiCp} / \mathrm{Al}$ composites were summarized. Wei et al. [15] prepared $\mathrm{SiCp} / \mathrm{Al6061}$ hybrid composites by vacuum hot pressing at $590{ }^{\circ} \mathrm{C}$ and $50 \mathrm{MPa}$, studied the microstructure and surface properties of the composites and their effects on the mechanical properties and thermal properties of the composites, and the machining performance was evaluated comprehensively. Sun et al. [16] studied the formation mechanism of particle damage in the processing of $\mathrm{SiCp} / \mathrm{Al}$ composites and the effect of particle damage on chip formation. And based on the different degree of particle damage in the chip formation process, three new chip formation conceptual models with different fracture types were proposed to visually describe the chip formation process in SiCp/Al composites.

Overall, most scholars have used the method of macroscopic grinding low volume fraction $\mathrm{SiCp} / \mathrm{Al}$ composites to study the effect of grinding force on the surface of ground materials, and established a simulation model to verify the correctness of grinding mechanism [17-19]. However, most scholars lacked of in-depth research on the sub-surface quality of high volume fraction SiCp/A12024 composites during grinding. In order to simulate the grinding process of $\mathrm{SiCp} / \mathrm{Al} 2024$ composites more accurately and observe the quality of the surface and the sub-surface, different grinding rake angles and different grinding depths are set by Abaqus software. Through the single-factor experiment method, the end surface grinding of the SiCp/Al2024 composite material with $60 \%$ reinforcement base particles is carried out, and the experimental results of the surface roughness are obtained, and the influence of the grinding depth on the surface and sub-surface quality after grinding is explained. The experimental results and the simulation results are mutually verified. Moreover, the influence of feed rate and grinding depth on the surface quality of the workpiece is discussed.

\section{Experiment design}

\subsection{Experiment condition}

$\mathrm{SiCp} / \mathrm{Al} 2024$ composite is selected as the workpiece, the volume fraction of $\mathrm{SiC}$ particles is $60 \%$, the particles are big and the hardness is high. And the average particle size of $\mathrm{SiC}$ particles is $40 \mu \mathrm{m}$, of which the smallest particle size is $20 \mu \mathrm{m}$ and the largest particle size is 60 $\mu \mathrm{m}$. The material characteristics of the workpiece are shown in Table 1.

Table 1 Workpiece material characteristics

\begin{tabular}{c|c}
\hline Density $\rho\left(\mathrm{kg} / \mathrm{m}^{3}\right)$ & 2970 \\
\hline Thermal diffusivity $\left(\mathrm{m}^{2} / \mathrm{s}\right)$ & $9.93 \times 10^{-5}$ \\
\hline Specific heat $\left(\mathrm{J} \cdot \mathrm{kg}^{-1} \cdot \mathrm{K}^{-1}\right)$ & 689 \\
\hline Thermal conductivity $\left(\mathrm{W} \cdot \mathrm{m}^{-1} \cdot \mathrm{K}^{-1}\right)$ & 203 \\
\hline Young's modulus $(\mathrm{GPa})$ & 206 \\
\hline Poisson's ratio & 0.24 \\
\hline Thermal expansion coefficient $\left({ }^{\circ} \mathrm{C}^{-1}\right)$ & $7.98 \times 10^{-6}$ \\
\hline
\end{tabular}

When $n$ is $14000 \mathrm{r} / \mathrm{min}, v_{\mathrm{w}}$ is $0.003 \mathrm{~m} / \mathrm{min}$, and $a_{\mathrm{p}}$ is $15 \mu \mathrm{m}$, the Matlab Software is used to simulate the groove of end surface grinding of $\mathrm{SiCp} / \mathrm{Al}$ composite, and the simulation result is shown in Figure 1(a). Meanwhile, under the same grinding parameter 
conditions, a grinding experiment is performed on the workpiece, and the microstructure of the workpiece is obtained as shown in Figure 1(b). Therefore, the simulation results and the observed experimental results mutually verify each other, so this series of experimental studies is feasible.

\section{Finished workpiece}
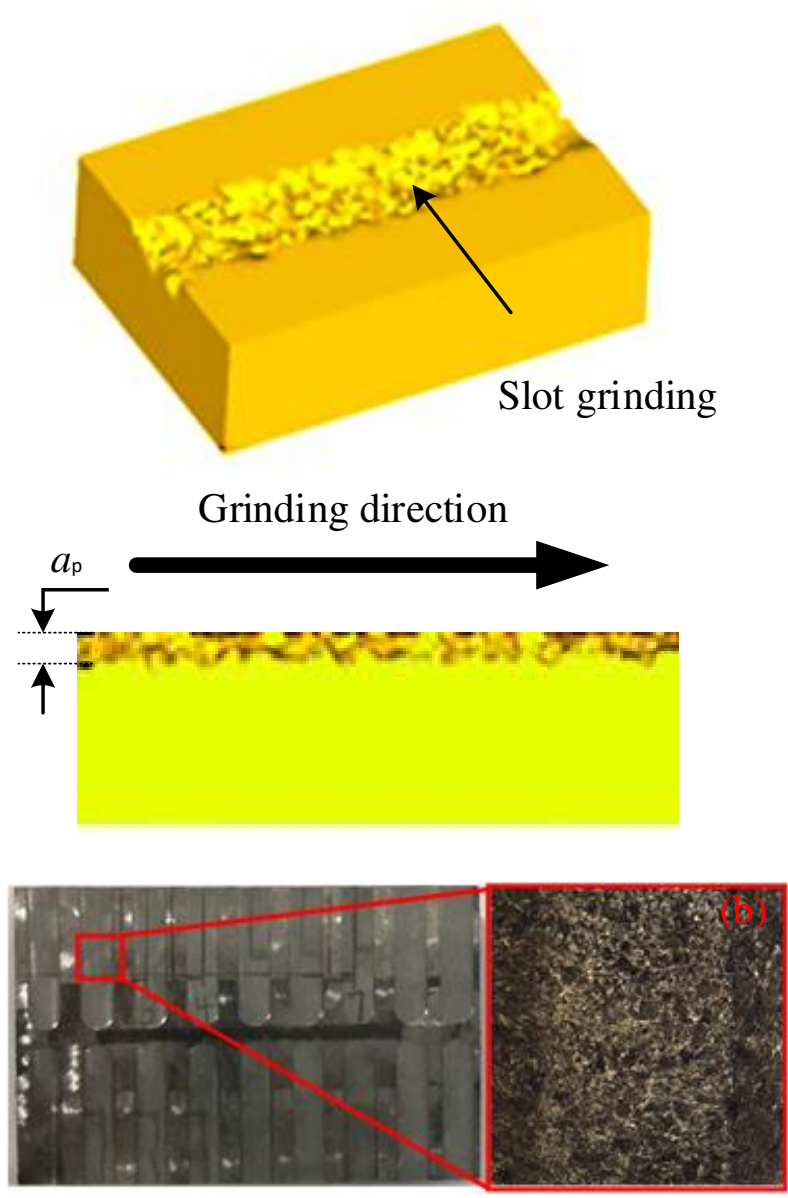

Fig. 1 Surface morphology of machined workpiece (a) Simulation of groove surface shape after machining (b) Morphology and microstructure of real surface

As shown in Figure 2, the micro-grinding experiment platform is set up. The machining equipment is a Beijing precision Carver400GA CNC machine, the size of the worktable is $490 \times 430 \mathrm{~mm}$, the spindle speed is up to $30000 \mathrm{rpm}$, and the positioning accuracy of $\mathrm{x} / \mathrm{y} / \mathrm{z}$ axis is $0.008 / 0.008 / 0.006 \mathrm{~mm}, \mathrm{x} / \mathrm{y} / \mathrm{z}$ axis repetitive positioning accuracy is $0.005 / 0.005 / 0.005 \mu \mathrm{m}$, maximum grinding rod feed rate is $6 \mathrm{~m} / \mathrm{min}$. $\mathrm{SiCp} / \mathrm{Al} 2024$ composites are ground by using electroplated diamond grinding rod. The grinding head diameter and grinding rod shank diameter is $3 \mathrm{~mm}$, the grinding rod mesh number is $\# 150$, and the average abrasive grain strength is $200 \mu \mathrm{m}$. In addition, the boron nitride is added to the grinding rod to improve the heat resistance and prevent sand loss during grinding, thus extending the service life effectively.

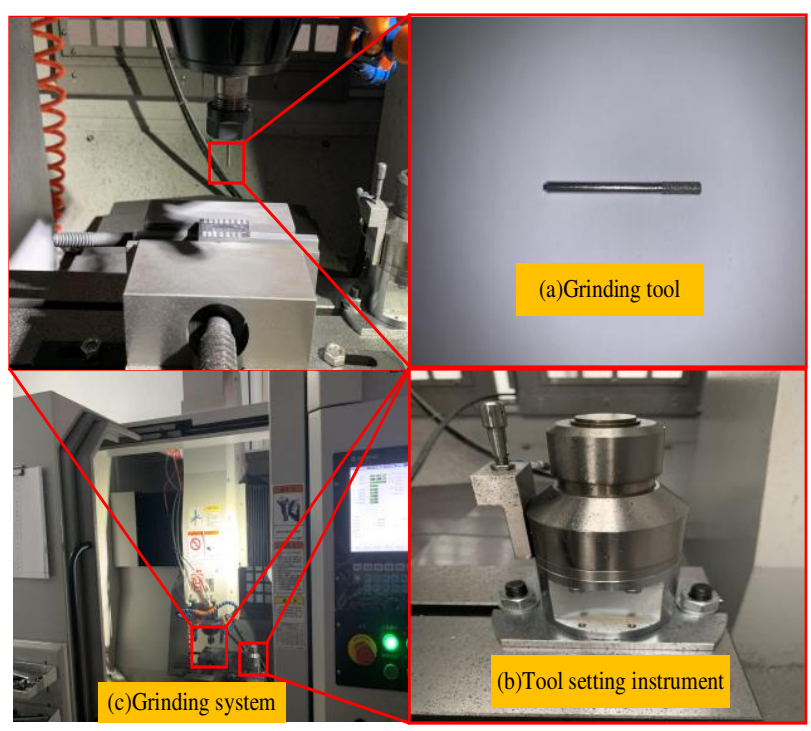

Fig. 2 Schematic diagram of grinding experiment system

The end surface grinding experiments are carried out on the Carver 400 high-precision engraving machine, and the Zeiss SIGMA 500 scanning electron microscope is used to observe the surface and subsurface quality of the processed workpiece. The equipment is shown in Figure 3. 


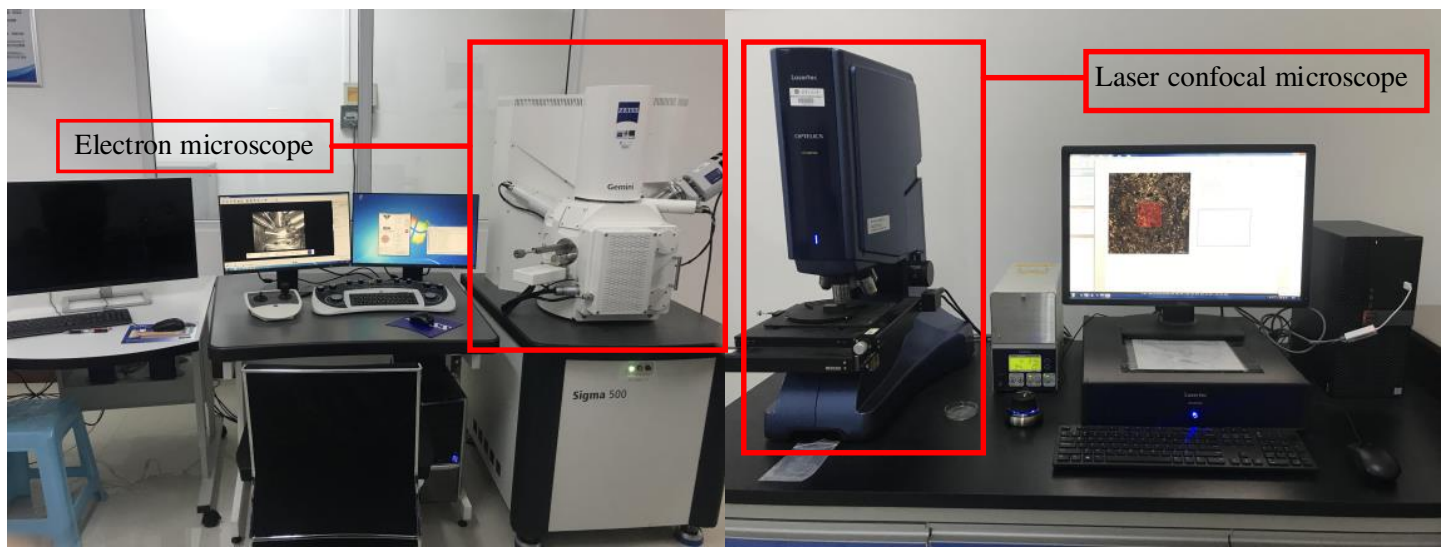

Figure 3 Schematic diagram of the microscope system

\subsection{Experimental procedure}

Through comparative analysis, the grinding mechanism of SiCp/Al2024 composite material is discussed. Simultaneously, in order to obtain more accurate experimental results, the grinding experiment adopts the dry grinding method [20-22], and the grinding process parameters are shown in Table 2.

Table 2 Grinding process parameters

\begin{tabular}{c|c}
\hline Conditions & Dosage \\
\hline Grinding rod type & electroplated diamond grinding rod \\
Grinding type & End surface grinding \\
Spindle speed & 14000 \\
$n /(\mathrm{r} / \mathrm{min})$ & \\
Feed rate & $0.003 、 0.005 、 0.007$ \\
$v_{\mathrm{w}} /(\mathrm{m} / \mathrm{min})$ & \\
Grinding depth & \\
$a_{\mathrm{p}} /(\mathrm{mm})$ & $0.015 、 0.02 、 0.025,0.03$ \\
Grinding process & \\
conditions & Drying grinding \\
\hline
\end{tabular}

In the grinding process, the spindle speed is 14000 $\mathrm{r} / \mathrm{min}$, the grinding depth is $10 \mu \mathrm{m}-30 \mu \mathrm{m}$, and the feed rate is $0.003,0.005$, and $0.007 \mathrm{~m} / \mathrm{min}$. The specific experimental data design is shown in Table 3.

\begin{tabular}{cccc}
\multicolumn{4}{l}{ Table 3 Grinding experiment Scheme } \\
\hline Number & $n /(\mathrm{r} / \mathrm{min})$ & $v_{\mathrm{w}} /(\mathrm{m} / \mathrm{min})$ & $a_{\mathrm{p}} /(\mu \mathrm{m})$ \\
\hline 1 & 14000 & 0.003 & 10 \\
2 & 14000 & 0.003 & 15 \\
3 & 14000 & 0.003 & 20 \\
\hline
\end{tabular}

\begin{tabular}{llll}
\hline 4 & 14000 & 0.003 & 25 \\
5 & 14000 & 0.003 & 30 \\
6 & 14000 & 0.005 & 10 \\
7 & 14000 & 0.005 & 15 \\
8 & 14000 & 0.005 & 20 \\
9 & 14000 & 0.005 & 25 \\
10 & 14000 & 0.005 & 30 \\
11 & 14000 & 0.007 & 10 \\
12 & 14000 & 0.007 & 15 \\
13 & 14000 & 0.007 & 20 \\
14 & 14000 & 0.007 & 25 \\
15 & 14000 & 0.007 & 30 \\
\hline
\end{tabular}

Figure 4 shows a schematic diagram of the grinding rod end surface grinding $\mathrm{SiCp} / \mathrm{Al} 2024$ composite material. After the grinding rod is used to determine the grinding depth along the $F_{\mathrm{z}}$ direction, the electroplated diamond grinding rod is uniformly ground from one side of the workpiece to the other at a constant feed rate and spindle speed. The yellow area in Figure 4 is the area where the grinding has been completed. This area is mainly processed by diamond particles on the end face of the grinding bar. Because the shape of the grinding rod is cylindrical and the grinding is continuous, a complete groove is left on the workpiece after grinding. The sub-surface quality is detected after the wire cutting in the grinding feed direction, and the surface of the groove is the testing position. When the spindle speed is constant, the surface quality and sub-surface quality of the workpiece will be greatly affected by changing the grinding depth of the grinding bar or the feed rate of the workpiece. Therefore, this experiment uses 15 groups of 
single factor experiments to illustrate the degree of influence of different grinding parameters on the quality of the first two. Meanwhile, when different grinding parameters are used to remove the workpiece as a whole, the removal ways of $\mathrm{SiC}$ reinforced particles and aluminum matrix are also different.

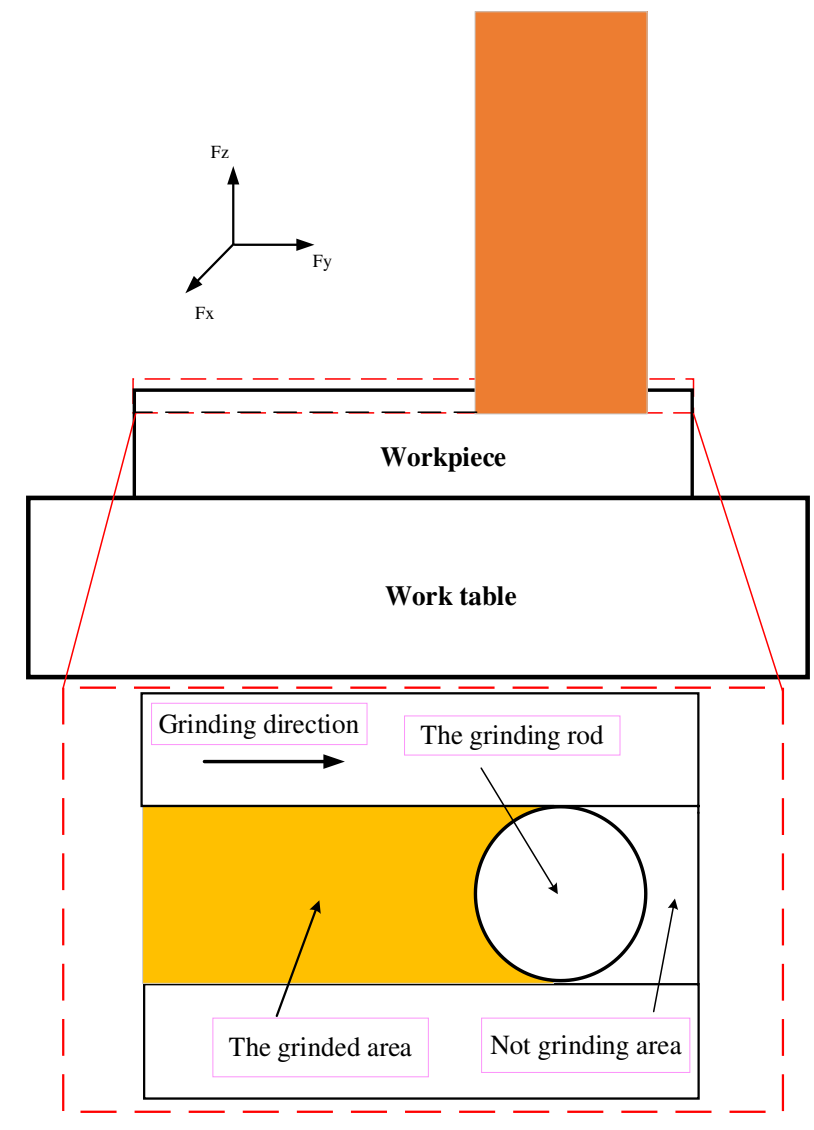

Fig. 4 Schematic illustration of face grinding

\section{Establishment and analysis of the simulation}

\subsection{Finite element model}

Fig. 5 is a finite element model for grinding $60 \% \mathrm{SiC}$ reinforced aluminum matrix composites. In this model, the transverse direction is $\mathrm{X}$ and the longitudinal direction is Y. The whole model consists of two parts, one is $\mathrm{SiCp} / \mathrm{Al}$ composite model, the other is single grain diamond tool model. In the simulation software, the workpiece is set as a two-dimensional rectangle with a length of $0.08 \mathrm{~mm}$ and a width of $0.04 \mathrm{~mm}$. And the $\mathrm{SiC}$ particles are simulated to be many different size circles with radius between $1 \mu \mathrm{m}$ and $5 \mu \mathrm{m}$. The total area of all circles accounts for $60 \%$ of the total area of the rectangle, which is consistent with the $60 \%$ volume fraction of $\mathrm{SiC}$ particles. In addition to the reinforced particles, the remaining part of the workpiece is aluminum matrix. The overall shape of the workpiece is a large number of circular areas surrounded by a rectangle. Furthermore, the grinding rake angle is more than $90^{\circ}$ in the tool grinding, so the tool is simplified into a right-angle trapezoid. And a circular arc with a radius of $1 \mu \mathrm{m}$ is set at the rake angle of the tool according to the parameters of actual grinding rod.

In the process of simulation modeling, the workpiece is divided into 11252 units, in which the area occupied by $\mathrm{SiC}$ particles is divided into 7808 units, and the aluminum matrix is divided into 3444 units. Because the removal mode of the composite is mainly determined by the $\mathrm{SiC}$ particles, the $\mathrm{SiC}$ particles are divided into fine grids, so the number of units formed in the region occupied by $\mathrm{SiC}$ particles is more than twice as large as that occupied by aluminum matrix. In addition, due to the high hardness of diamond particles, the tool in the simulation is set to a rigid body, so it does not require mesh division.

Similarly, due to the grinding process of slip and other aspects of the characteristics, it is necessary for the workpiece and tools for a variety of constraints in this simulation process. Firstly, for the workpiece, the bottom and most of the left and right sides are constrained (the red triangle in the figure is the constraint symbol) to ensure that the simulation is running properly.Secondly, it is given an initial velocity to the left which makes it cut continuously from right to left in the horizontal direction in the motion setting of the tool.

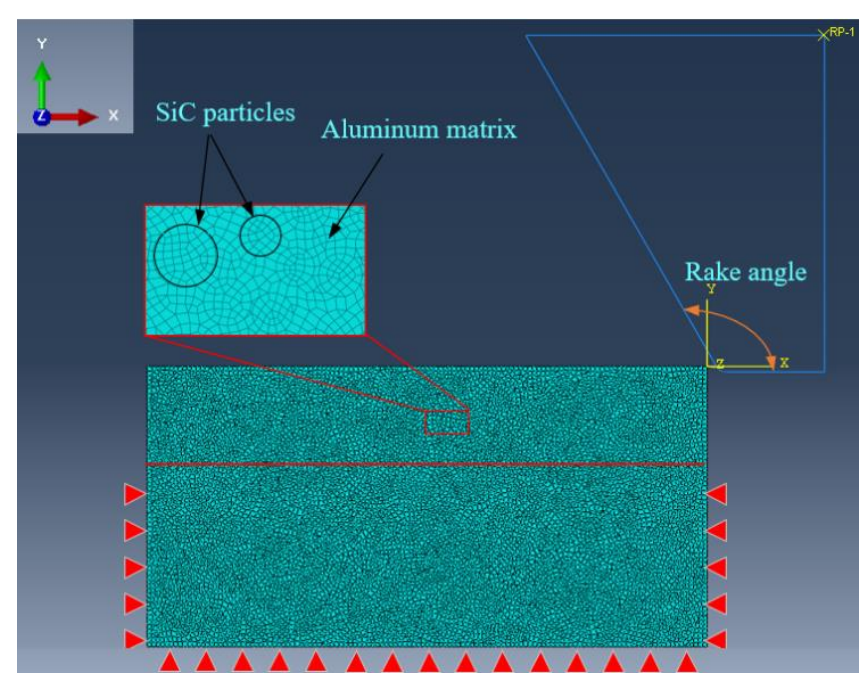

Fig. 5 Finite element model of grinding SiCp/Al 


\subsection{Matrix material}

According to Hooke's law, $\mathrm{SiC}$ particles in $\mathrm{SiCp} / \mathrm{A} 12024$ composites are defined as perfectly elastic materials. In this paper, the model of $\mathrm{SiC}$ composite is established, and the brittle fracture and extrusion dislocation of $\mathrm{SiC}$ particles are analyzed by finite element method. In the process of rod grinding composite materials, relative motion occurs, which causes friction resistance, so the temperature of the workpiece increases greatly, resulting in large strain on the material to be processed. Johnson and Cook [23] proposed Johnson-Cook (J-C) constitutive equation based on the simulation of matrix material. In addition, Akbari et al [24] improves the Johnson-Cook damage limit criterion. Johnson-Cook constitutive model can accurately describe the stress-strain relationship of metal materials under large strain rate. The three parameters of strain hardening, strain rate hardening and temperature softening are combined to express the deformation of the material in the process of machining. The material constitutive model can be expressed as:

$$
\sigma=\left(A+B \varepsilon_{\mathrm{p}}^{\mathrm{n}}\right)\left[1+C \ln \left(1+\frac{\varepsilon}{\varepsilon_{0}}\right)\right]\left[1-\left(\frac{T-T_{0}}{T_{\text {melt }}-T_{0}}\right)^{m}\right]
$$

Where, $\sigma$ is the Misses flow stress, $A$ is the initial yield stress, $B$ is the strain hardening parameter of the material, $C$ is the strengthening parameter of material strain rate, $n$ is the hardening index, $m$ is the thermal softening index of the material. $T_{\text {melt }}$ is the temperature of the material's melting point. $\mathrm{T}_{0}$ is room temperature. Among them, $A, B, C, n$ and $m$ need to be determined by the separation of the Hopkinson pressure bar (SHPB) experiment, and the material parameters are shown in Table 4.

Table 4 J-C constitutive model parameters of SiC/Al Composites

\begin{tabular}{ccccccc}
\hline$A(\mathrm{MPa})$ & $B(\mathrm{MPa})$ & $C$ & $n$ & $m$ & $T_{\text {melt }}\left({ }^{\circ} \mathrm{C}\right)$ & $T_{0}\left({ }^{\circ} \mathrm{C}\right)$ \\
\hline 265 & 526 & 0.06 & 0.325 & 1.95 & 720 & 20 \\
\hline
\end{tabular}

The Johnson-cook separation criterion is used to produce the failure when the strain at the integration node reaches a predetermined critical value. When the failure parameter $(\omega)$ is greater than one, the failure of the material can be assumed. If all points fail in the model, the material mesh will be cut off and detached from the workpiece. The failure parameter can be written as:

$$
\omega=\sum \frac{\Delta \varepsilon \frac{\mathrm{p} l}{f}}{\varepsilon \frac{p l}{f}}
$$

Where, $\Delta \varepsilon \frac{p l}{f}$ is the change in strain per incremental stepper unit time, $\varepsilon \frac{p l}{f}$ refers to the failure strain, which is affected by unit strain rate, hydrostatic stress Misses deviation ratio and unit temperature.

$$
\varepsilon \frac{p l}{f}=\left[D_{1}+D_{2} \exp \left(D_{3} \frac{p}{q}\right)\right]\left[1+D_{4} \ln \left(\frac{\varepsilon \frac{p l}{f}}{\varepsilon_{0}}\right)\right] \times\left(1+D_{5} \theta\right)
$$

Where $\mathrm{M}_{1}-\mathrm{M}_{5}$ is the coefficient of failure, and the parameters are shown in Table 5 .

Table $5 \mathrm{~J}-\mathrm{C}$ model failure parameter of $\mathrm{SiC} / \mathrm{Al}$ Composites

\begin{tabular}{ccccc}
\hline $\mathrm{M}_{1}$ & $\mathrm{M}_{2}$ & $\mathrm{M}_{3}$ & $\mathrm{M}_{4}$ & $\mathrm{M}_{5}$ \\
\hline 0.226 & 0.14 & -1.6 & 0.022 & 0 \\
\hline
\end{tabular}

\subsection{Analysis of the simulation results}

The influence of different grinding rake angle on the simulation results should be considered because the grinding rod is rotary grinding and the distribution of diamond particles is not uniform on the grinding rod. In this simulation, the tool rake angle is set to $105^{\circ}, 120^{\circ}$, $135^{\circ}$ and $150^{\circ}$, respectively, to get more accurate simulation results to illustrate the removal of composite materials. When $n$ is $14000 \mathrm{r} / \mathrm{min}, v_{\mathrm{w}}$ is $0.005 \mathrm{~m} / \mathrm{min}$ and $a_{\mathrm{p}}$ is $20 \mu \mathrm{m}$ and $30 \mu \mathrm{m}$ respectively, the simulation parameters are shown in Table 6 .

Table 6 Simulation parameters

\begin{tabular}{cccccc}
\hline$a_{\mathrm{p}} / \mu \mathrm{m}$ & 20 & 20 & 20 & 20 & 30 \\
\hline Angle $^{\circ}$ & 105 & 120 & 135 & 150 & 105 \\
\hline
\end{tabular}


When $n=14000 \mathrm{r} / \mathrm{min}, v_{\mathrm{w}}=0.005 \mathrm{~m} / \mathrm{min}, a_{\mathrm{p}}=$ $20 \mu \mathrm{m}$ and the tool rake angle is set at $105^{\circ}$, the two-dimensional simulation model of diamond bar grinding $\mathrm{SiCp} / \mathrm{A} 12024$ composites is shown in Fig. 6(a). It can be seen from the diagram that the removal mode of aluminum matrix is plastic removal, while the removal mode of silicon carbide particles is mainly particle crushing and particle pulling out. When the bottom of the tool cuts through the top or upper middle parts of the particles, the particles are subjected to larger stress transfer to produce cracks until they are broken, and the surface quality is affected to some extent. When the bottom surface of the tool cuts through the middle or lower middle parts of the particles, the particles are pulled out as a whole, forming large pits on the processed surface, making the surface quality worse.

When $a_{\mathrm{p}}$ increases from $20 \mu \mathrm{m}$ to $30 \mu \mathrm{m}$, the two-dimensional simulated topography is shown in Figure 6(b). The figure shows that the removal of aluminum matrix is still plastic removal, while the removal of silicon carbide particles is particle disintegration, particle extraction and particle crushing. When the grinding depth increases, the resistance of the workpiece will increase, and the stress will transfer to the sub-surface layer, which will make the particles bear more stress, so some particles will be broken, therefore, it is necessary to study the sub-surface quality.

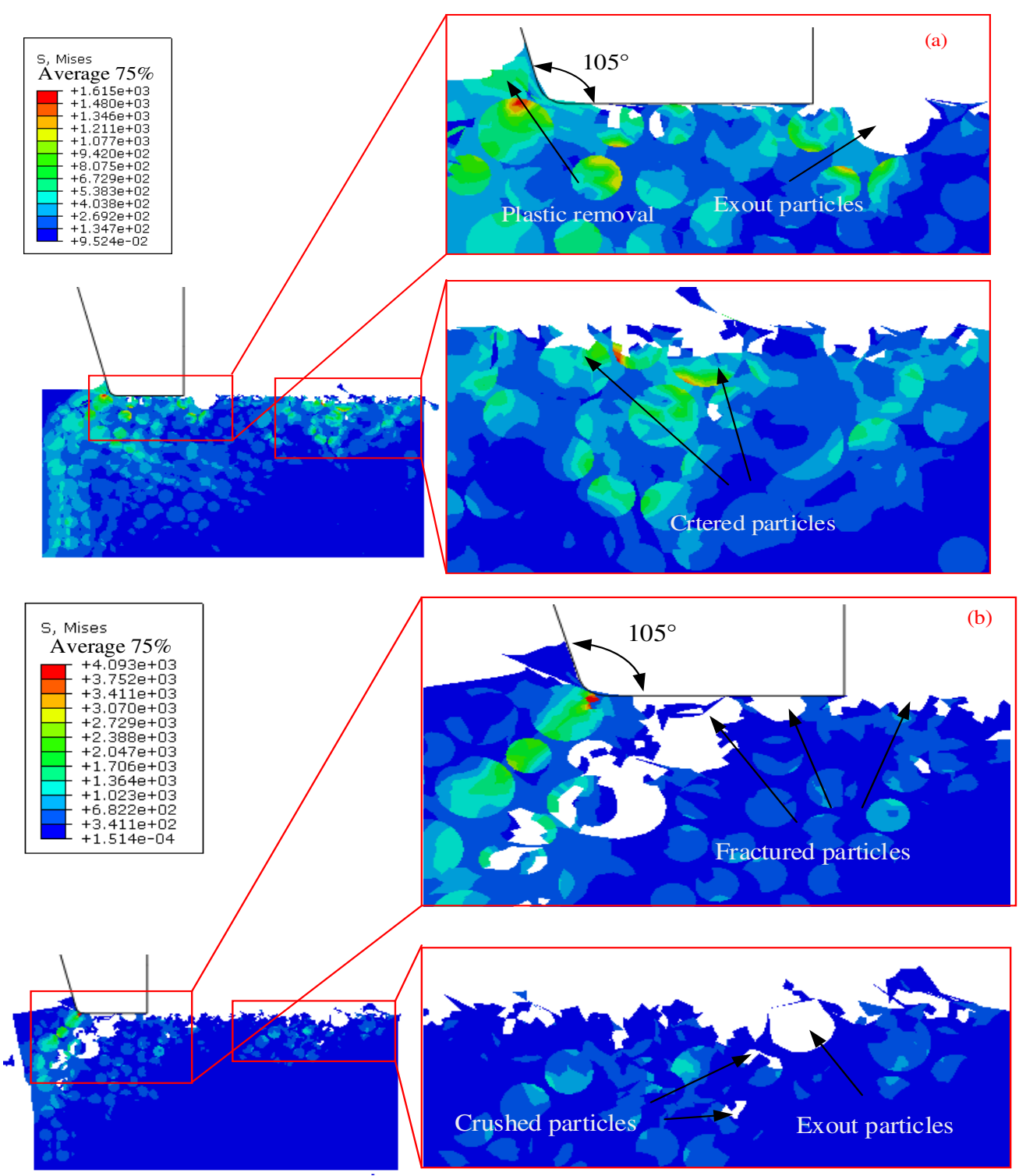

Fig. 6 Two-dimensional simulation topography at different grinding depths (a) $a_{\mathrm{p}}=20 \mu \mathrm{m}$ (b) $a_{\mathrm{p}}=30 \mu \mathrm{m}$ 
When $n=14000 \mathrm{r} / \mathrm{min}, v_{\mathrm{w}}=0.005 \mathrm{~m} / \mathrm{min}, a_{\mathrm{p}}=$ $20 \mu \mathrm{m}$, and the tool rake angle is set to $120^{\circ}$, the two-dimensional simulation model of diamond grinding rod grinding $\mathrm{SiCp} / \mathrm{A} 12024$ composite is shown in Figure 7(a). When the rake angle of the tool increases from $105^{\circ}$ to $120^{\circ}$, it is obvious that the number of particles crushed increases indirectly by the tool, and the maximum stress of the process reaches $3 \times 10^{3} \mathrm{MPa}$. When the tool rake angle increases, the extrusion pressure of the tool rake face increases to the workpiece, so the stress of the particle increases inside the workpiece, which leads to the increase of the number of particles crushed indirectly. When the cutter moves to the end of the workpiece, the cutter tears the workpiece. The depth of tearing is shown in Figure 7(a). The internal tensile stress of the workpiece to the end is less than the tensile stress of the workpiece to other positions. When the shearing force generated by the tool on the workpiece is greater than the tensile stress of the workpiece to the end, it will cause partial tearing of the end.

When the three parameters of grinding remain unchanged, and the rake angle of the tool increases to $135^{\circ}$, the two-dimensional grinding simulation model of the workpiece is shown in Figure 7(b). It can be seen from the figure that the surface quality of the processed area has significantly deteriorated, because the processed surface of the workpiece has a large number of pits formed by the collapsed $\mathrm{SiC}$ particles. Meanwhile, as the rake angle of the tool increases, the shear force on the rake face of the workpiece increases, so the stress on the $\mathrm{SiC}$ particles inside the workpiece increases. When the stress exceeds the bearing capacity of the reinforcing particles, $\mathrm{SiC}$ particles will break up, resulting in a decrease in the quality of the sub-surface layer. When the tool angle is $135^{\circ}$, the shear stress on the rake face of the tool on the workpiece instantly reaches the maximum value of $7.5 \times 10^{3} \mathrm{MPa}$. When the depth of the tool tearing the end of the workpiece reaches the maximum, the depth is 2.5 times the depth of the tool tearing the workpiece with a $120^{\circ}$ rake angle.

Under the premise that the various grinding parameters remain unchanged, when the rake angle of the tool is increased to $150^{\circ}$, the two-dimensional grinding simulation model of $\mathrm{SiCp} / \mathrm{A} 12024$ composite is shown in Figure 7(c). Simultaneously, as the shear stress of the tool on the workpiece continues to increase, the crushed reinforcement particles continue to increase, so the surface quality and sub-surface quality become worse. Although the longitudinal shear force is increased, the transverse shear force is reduced compared to Fig. 7(b), so the tearing depth of the tool to the end of the workpiece is basically the same as that of Fig. 7(a). 

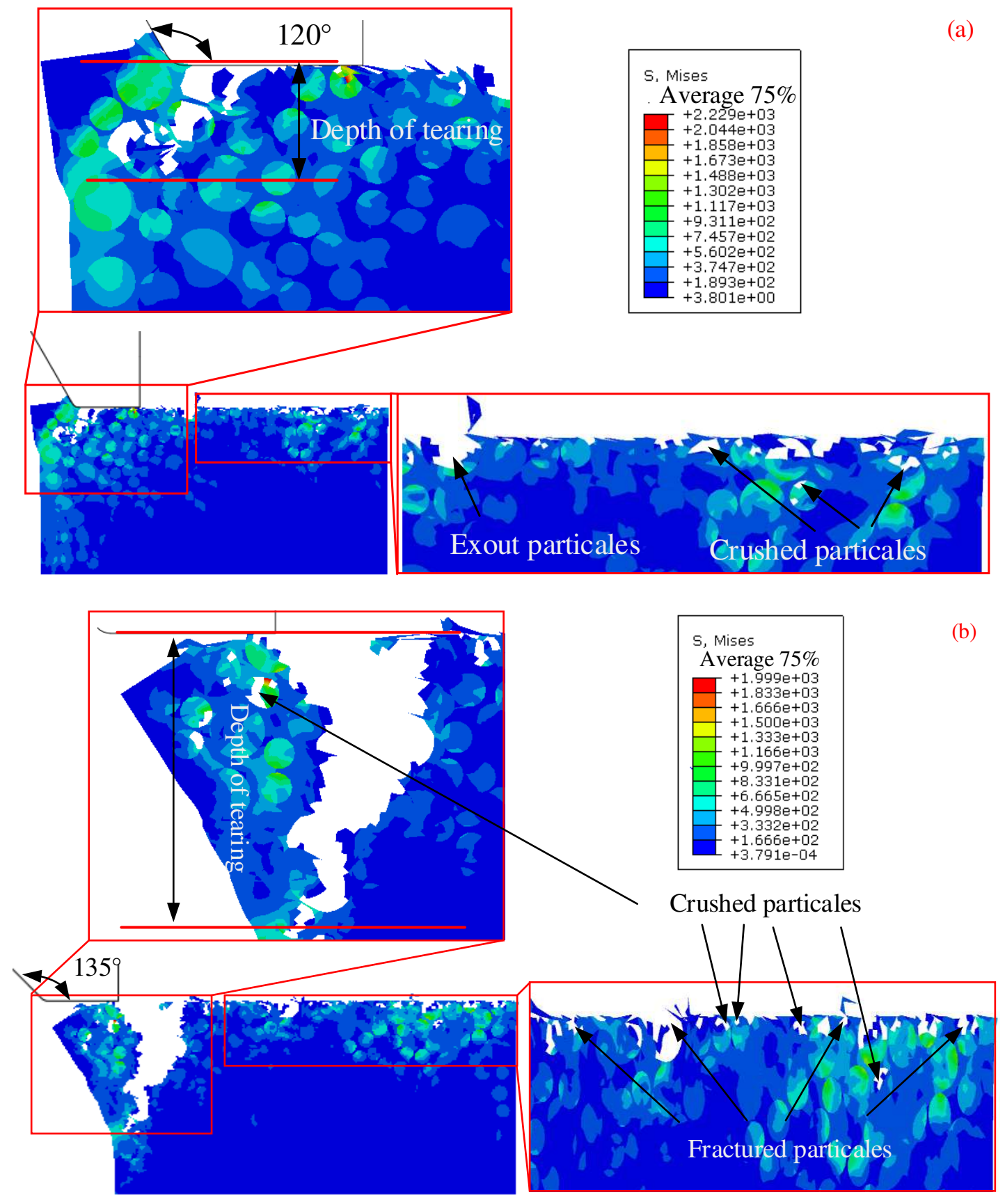


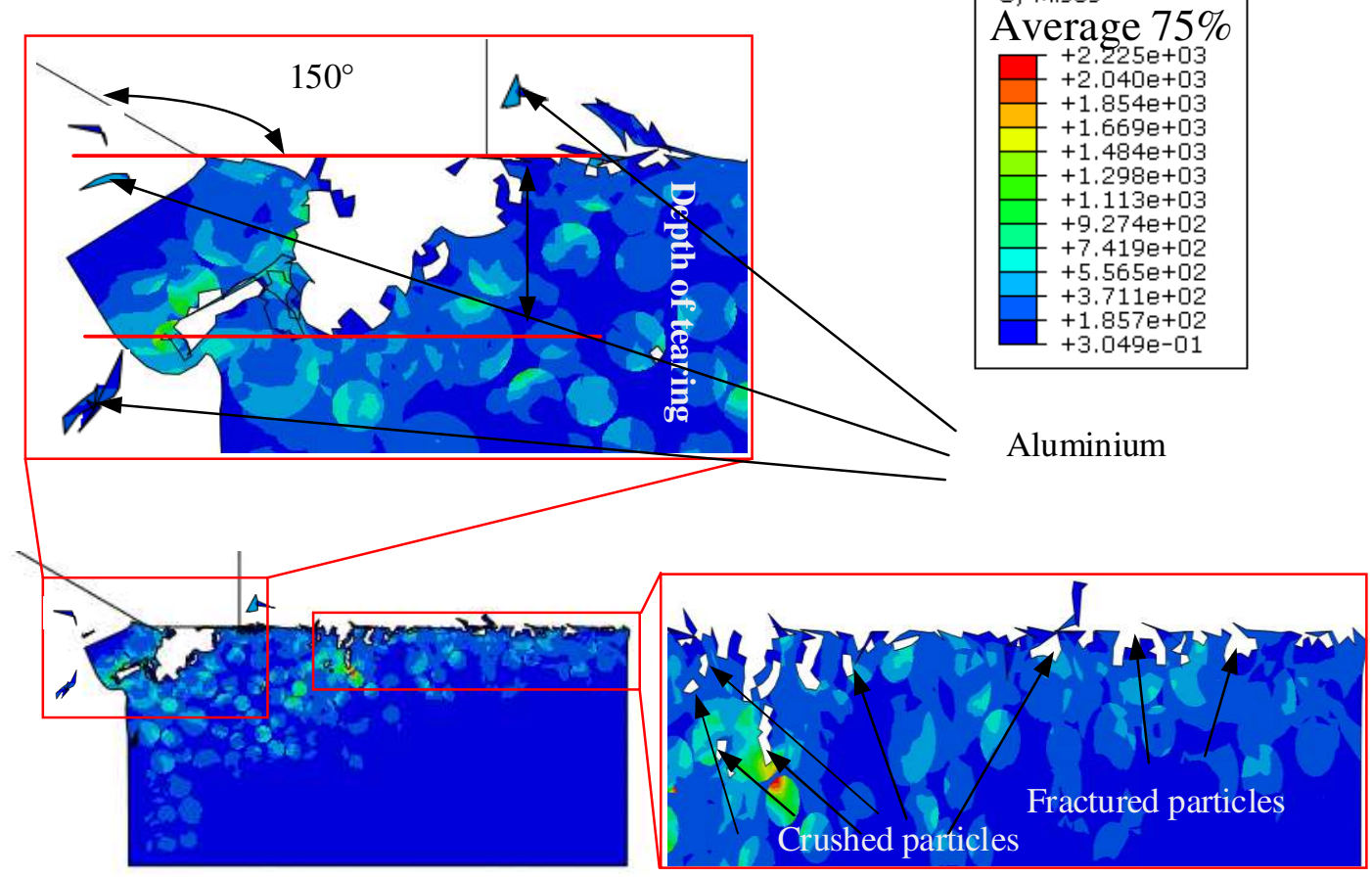

Fig. 7 Two-dimensional simulation topography under different rake angles (a) The angle is $120^{\circ}$ (b) The angle is $135^{\circ}$ (c) The angle is $150^{\circ}$

\section{Results and discussion of experiments}

\subsection{Experimental results}

Since the grinding depth $\left(a_{\mathrm{p}}\right)$ has a greater influence on the surface roughness $(R a)$, the surface quality is studied under the change of grinding depth. A $3 \mathrm{~mm}$ diameter electroplated diamond grinding rod is used to grind the $\mathrm{SiCp} / \mathrm{A} 12024$ composite material on the Carver 400 precision engraving machine. According to the experimental scheme in Table 3, the experimental results of surface roughness are obtained, as shown in Fig. 8.

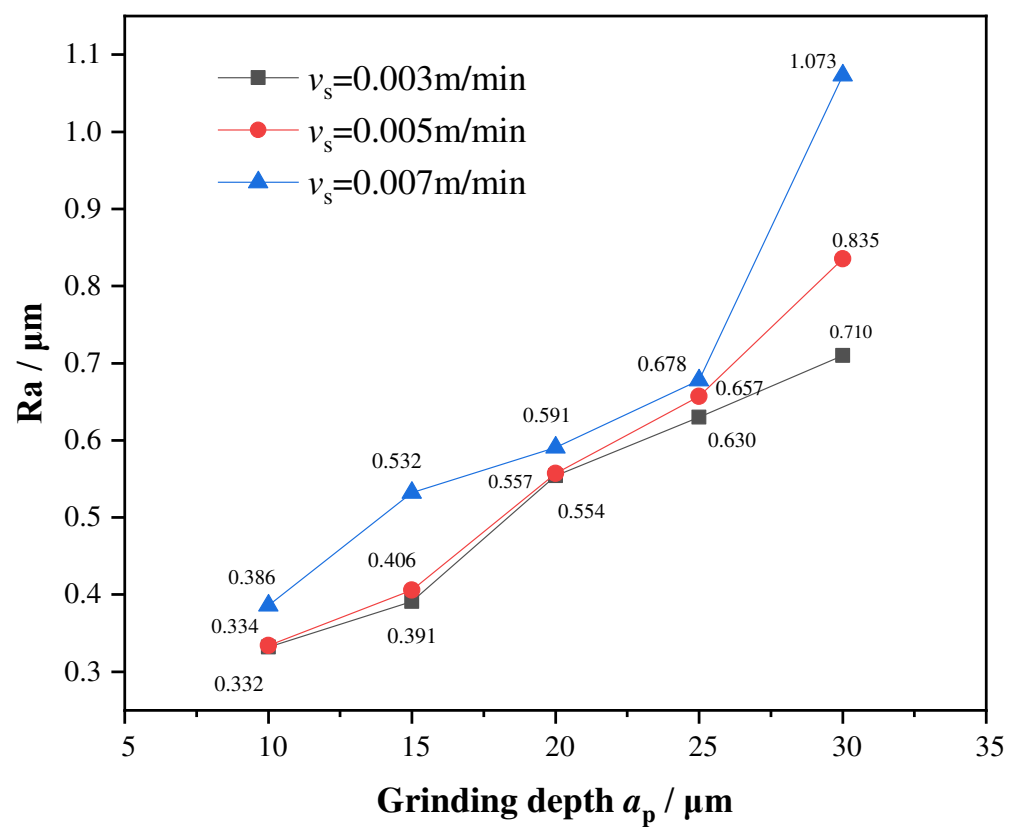

Fig. 8 Surface roughness values under different grinding parameters 
It can be seen from Figure 8 that when the spindle speed $(n)$ and the grinding rod feed rate $\left(v_{\mathrm{w}}\right)$ remain unchanged, as the grinding depth increases, the surface roughness also increases. When the grinding depth increases, the normal grinding force and the tangential grinding force increase at the same time, and the number of broken SiC particles on the surface of the workpiece increases, so the surface roughness is on the rise. When $v_{\mathrm{w}}=0.003 \mathrm{~m} / \mathrm{min}$, when $a_{\mathrm{p}}$ increases from $10 \mu \mathrm{m}$ to 30 $\mu \mathrm{m}$, the value of $R a$ rises from $0.332 \mu \mathrm{m}$ to $0.71 \mu \mathrm{m}$. When $a_{\mathrm{p}}$ increased from $15 \mu \mathrm{m}$ to $20 \mu \mathrm{m}$, the $R a$ increased the most, and its value rose from $0.391 \mu \mathrm{m}$ to $0.554 \mu \mathrm{m}$. When $v_{\mathrm{w}}=0.005 \mathrm{~m} / \mathrm{min}$, under the same $a_{\mathrm{p}}$ increment condition, the value of $R a$ rises from $0.334 \mu \mathrm{m}$ to $0.835 \mu \mathrm{m}$. When $v_{\mathrm{w}}=0.007 \mathrm{~m} / \mathrm{min}$, under the same $a_{\mathrm{p}}$ increment condition, the value of $R a$ rises from $0.386 \mu \mathrm{m}$ to $1.073 \mu \mathrm{m}$. Under the above two feed rates, when $a_{\mathrm{p}}$ increases from $25 \mu \mathrm{m}$ to $30 \mu \mathrm{m}$, the $R a$ increases the most, with increments of $0.178 \mu \mathrm{m}$ and $0.395 \mu \mathrm{m}$ respectively. In general, when $a_{\mathrm{p}}$ exceeds $25 \mathrm{um}$, the $R a$ increases significantly, and it is recommended to control the $a_{\mathrm{p}}$.

\subsection{Analysis of experimental results based on 3D nephogram}

The Zeiss SIGMA 500 scanning electron microscope is used to detect the microstructure of the three groove-shaped processed surfaces, and the corresponding 3D nephograms are formed to better propose the surface mechanism of the processed workpiece. Under $n=14000$ $\mathrm{r} / \mathrm{min}, v_{\mathrm{w}}=0.007 \mathrm{~m} / \mathrm{min}$, and $a_{\mathrm{p}}$ of $10 \mu \mathrm{m}, 20 \mu \mathrm{m}$ and 30 $\mu \mathrm{m}$ respectively, the local microstructure and $3 \mathrm{D}$ nephogram of the machined surface are shown in Figure
9.

In Figure 9(a), the value of $R a$ is $0.386 \mu \mathrm{m}$. It can be seen from the part showing the microstructure that more pits and shallower gullies are left on the processed surface. As the surface roughness is low, the pits are formed by fragmentation of $\mathrm{SiC}$ particles. The aluminum matrix is a plastic material, and its removal method is plastic removal, so the tool abrasive grains leave scratches on the matrix and form a shallower ravine. However, because the value of $a_{\mathrm{p}}$ is small, the depth of the ravine is small. So the surface quality is not greatly affected. And it can be fully verified from the 3D nephogram that there are shallow ravines and a few pits on the surface, and the surface quality is good.

In Figure 9(b), the value of $R a$ is $0.591 \mu \mathrm{m}$. It can be seen from the microstructure display that most of the pits are deep, so the pits here are caused by a small number of SiC particles broken and most $\mathrm{SiC}$ particles pulled out as a whole. This is fully verified by the corresponding $3 \mathrm{D}$ nephogram. Besides, the $3 \mathrm{D}$ nephogram shows that very few of the spikes are formed on machined surfaces after plastic removal of the aluminum matrix or $\mathrm{SiC}$ particles are broken.

In Figure 9(c), the value of $R a$ is $1.073 \mu \mathrm{m}$. From the pits in the $3 \mathrm{D}$ nephogram, it can be seen that there are three forms of $\mathrm{SiC}$ particles: breaking, pulling out and crushing, and most of the particles are already incomplete. In addition, due to the large value of ap, the scratches produced are deeper, and multiple deep gullies have been revealed, causing serious damage to the surface quality. At this time, the Ra of the processed workpiece has reached the maximum value.

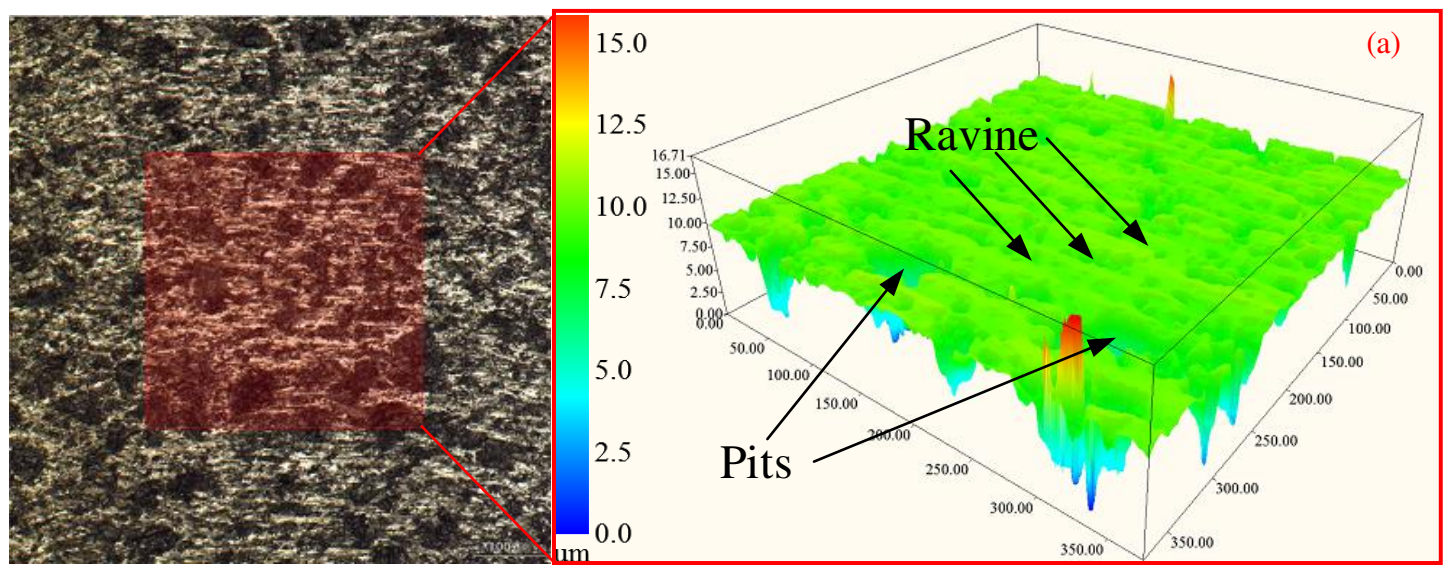



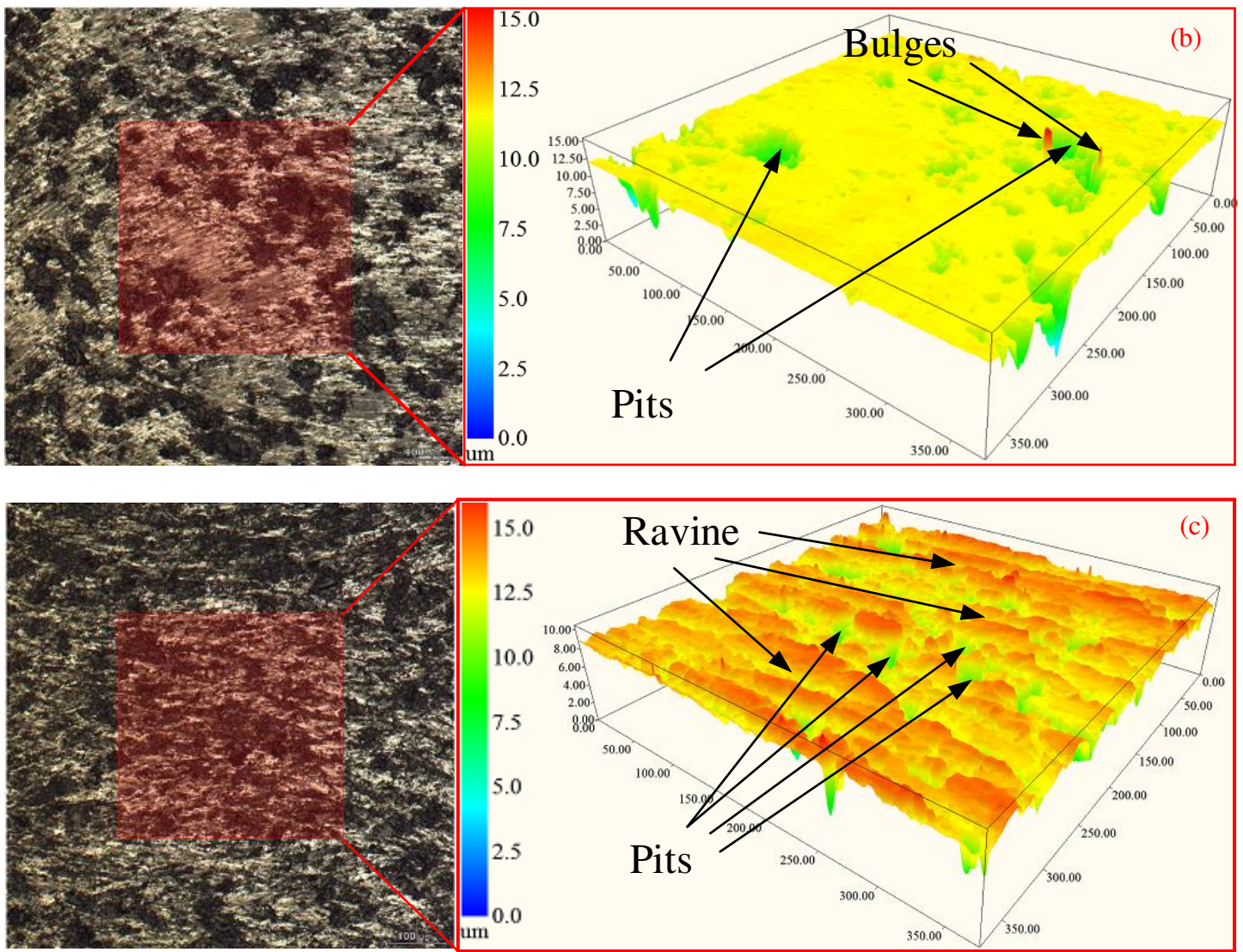

Fig. 9 Surface roughness microstructure and 3D nephogram (a) $a_{\mathrm{p}}=10 \mu \mathrm{m}$ (b) $a_{\mathrm{p}}=20 \mu \mathrm{m}$ (c) $a_{\mathrm{p}}=30 \mu \mathrm{m}$

From the perspective of experimental results, the collapse of particles, pull-out of particles and the depth of scratches are all important factors to affect the surface quality. To improve the surface quality of processed workpieces, smaller $\mathrm{SiC}$ particles can be selected as reinforcement particles. In terms of the effect of ap on the surface quality, the multi-step processing can lower the value of $R a$.

\subsection{Analysis of experimental results based on sub-surface microstructure}

In order to study the quality of the sub-surface layer, the experimental parameters are set, as shown in Table 7. After the grinding is completed, wire cutting is performed along the grinding feed direction and the quality of the sub-surface layer is tested. And the experimental results are shown in Figure 10.

Table 7 Experimental parameter

\begin{tabular}{llll}
\hline & \multicolumn{3}{c}{ Experimental factors } \\
\cline { 2 - 3 } Serial number & $v_{\mathrm{w}}(\mathrm{m} / \mathrm{min})$ & $a_{\mathrm{p}}(\mu \mathrm{m})$ \\
\hline
\end{tabular}

\begin{tabular}{cccc}
\hline 1 & 14000 & 0.005 & 10 \\
2 & 14000 & 0.005 & 20 \\
3 & 14000 & 0.005 & 30 \\
\hline
\end{tabular}

As shown in Figure 10(a), in the case of $a_{\mathrm{p}}=10 \mu \mathrm{m}$, the thickness of the damaged layer of the workpiece is small, and some cracks and a small amount of voids will occur close to the surface; Meanwhile extremely a few cracks and voids will also appear at the position far from the processed surface. When the end face of the grinding rod grinds the surface of the workpiece, the closer it is to the surface, the greater the stress transfer and the better the stress transfer effect. Therefore, the farther away from the surface, the greater the degree of damage. When the end face of the grinding rod grinds the surface of the workpiece, the closer it is to the surface, the greater the stress transfer and the better the stress transfer effect, so the closer the surface is, the greater the degree of damage. Since the strain required to form a cavity is greater than the strain required to form a crack, most of the cavity is formed close to the surface. Similarly, as the distance from the surface gets farther and farther, fewer cracks are 
produced.

Compared with Fig. 10(a), the thickness of the damaged layer of the workpiece is increased, and the length of the crack generated close to the surface is also increased in Fig. 10(b). Meanwhile, the number of cavities close to the processed surface also increases. Under the condition of $a_{\mathrm{p}}=20 \mu \mathrm{m}$, because the normal grinding force on the end face of the grinding rod increases, the strain increases on the workpiece, which leads to a larger length of cracks and most cavities near the surface layer. In general, the degree of damage to the sub-surface layer is significantly greater than the result shown in Figure 10(a).

When the grinding depth is $30 \mu \mathrm{m}$, the sub-surface damage of the workpiece is shown in Figure 10(c). The processed surface quality is poor, and the quality of the sub-surface layer is lower than the above two cases. In the place closer to the machined surface, the number of cracks increases while accompanied by a large number of cavities. A large number of cracks are also generated in the place far away from the processed surface, and the number of voids is also significantly increased compared to Figure 10(a) and Figure 10(b).

When the spindle speed and feed rate are constant, the normal grinding force of the end face of the grinding rod on the workpiece increases with the increase of $a_{\mathrm{p}}$, so the stress on the subsurface layer increases. For $\mathrm{SiC}$ particles with fragile properties, when it is subjected to a large enough stress, the particles will first crack until the crack penetrates the particle itself, and finally collapse. Therefore, when the spindle speed and the feed rate are unchanged, $a_{\mathrm{p}}$ is inversely proportional to the quality of the sub-surface layer. The larger the $a_{\mathrm{p}}$, the worse the quality of the sub-surface layer. Because the stress transmission gradually decreases with the increase of distance in this material, the farther away from the surface, the better its quality. And because the stress required to form the cavity is greater, the number of cavities formed closer to the processed surface is more than the number of cavities formed at a position farther from the processed surface. When the stress is not enough to break the $\mathrm{SiC}$ particles, the cracks are left in the sub-surface layer of the $\mathrm{SiCp} / \mathrm{Al}$ composite material. The length of the crack is determined by the distance between the particle location and the machined surface. The longer the distance between the two, the shorter the crack length, and vice versa.

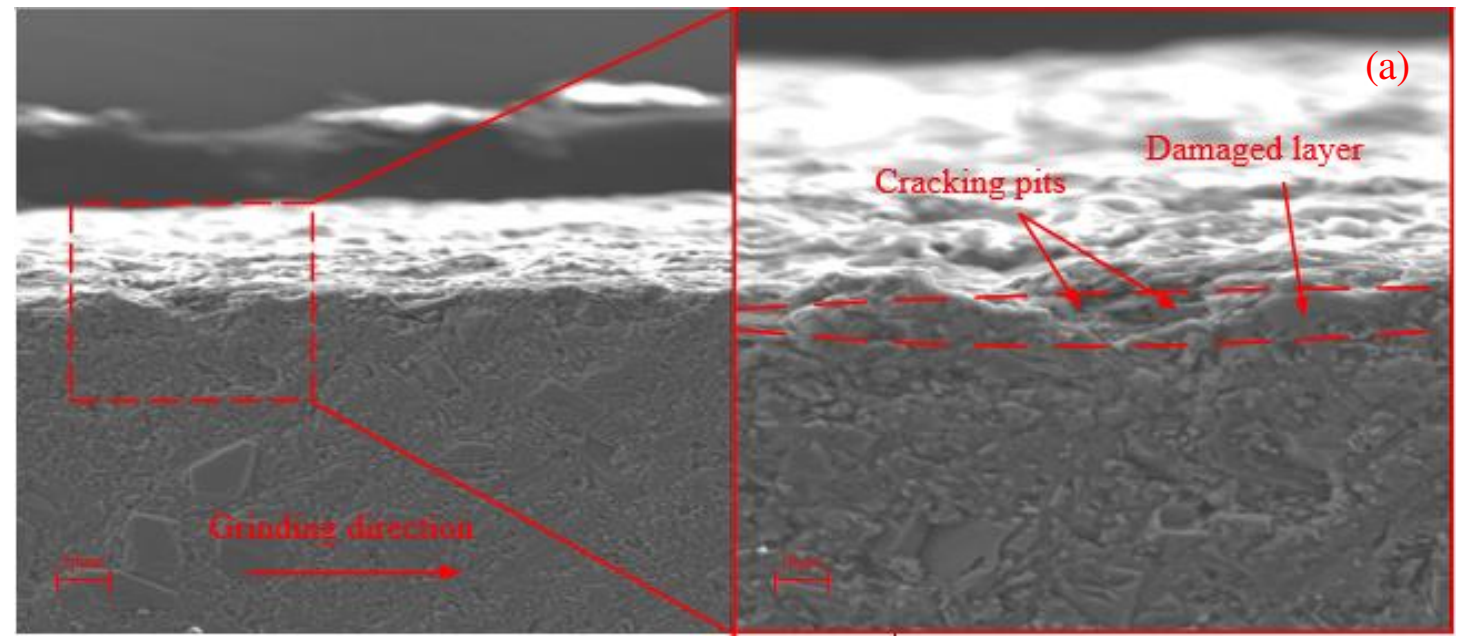



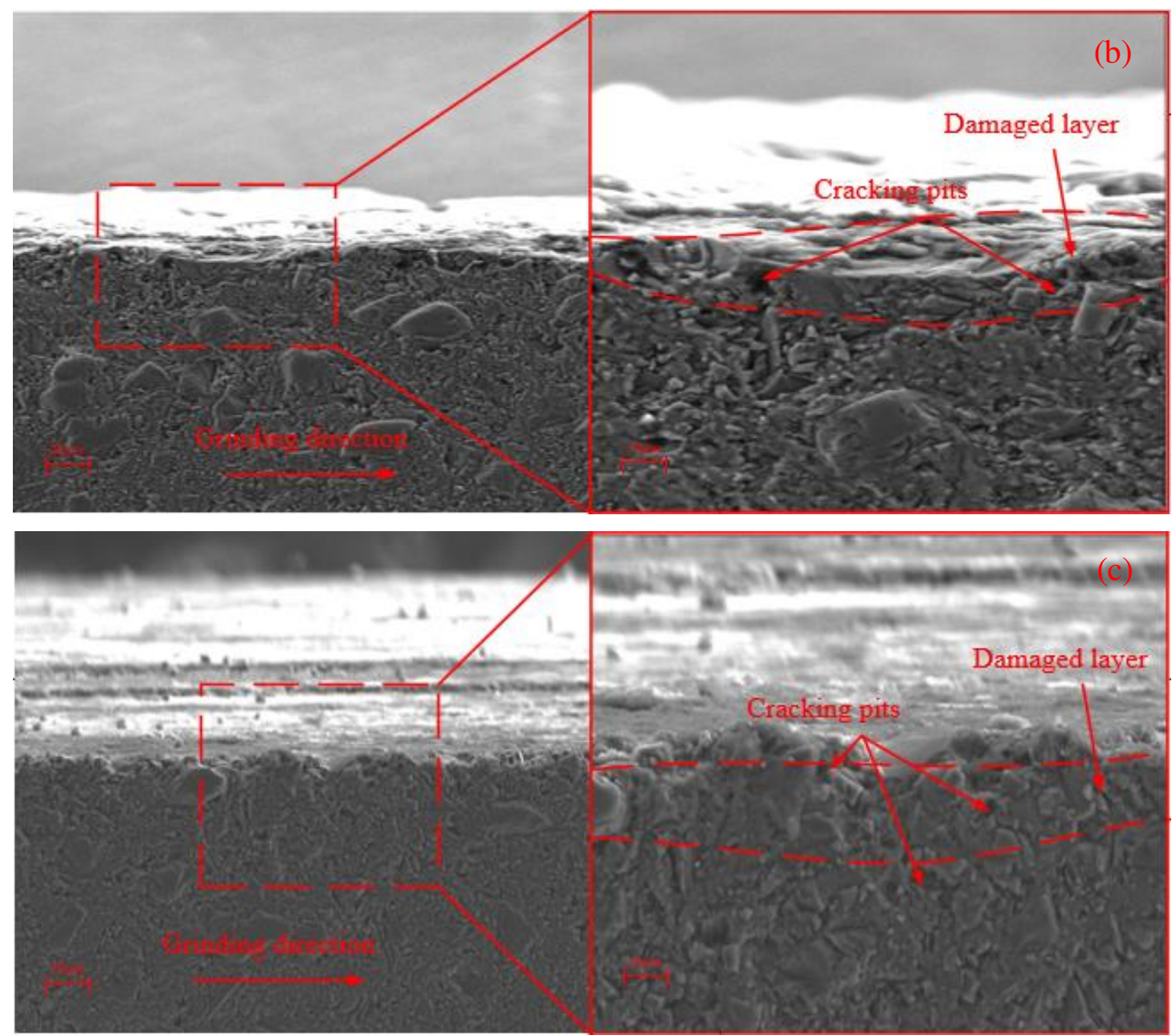

Fig. $10 \mathrm{Sub}$-surface microstructure of SiCp/Al composite (a) $a_{\mathrm{p}}=10 \mu \mathrm{m}$ (b) $a_{\mathrm{p}}=20 \mu \mathrm{m}$ (c) $a_{\mathrm{p}}=30 \mu \mathrm{m}$

\section{Conclusions}

(1) Based on the grinding experiment of SiCp/Al2024 composite material ( $\mathrm{SiC}$ particles accounted for $60 \%$ by volume fraction), a grinding rod end face grinding experiment platform is built. And different grinding parameters are selected for 15 groups of single factor experiments, and Ramax is obtained as $1.073 \mu \mathrm{m}$, the $R a_{\min }$ is $0.332 \mu \mathrm{m}$. Besides, the degree of influence of grinding depth on surface roughness is greater than the degree of influence of feed rate on surface roughness.

(2) Two-dimensional simulation models with four different angles of $105^{\circ}, 120^{\circ}, 135^{\circ}$ and $150^{\circ}$ are established, and the grinding process is simulated, and the material removal mechanism and the crushing state of $\mathrm{SiC}$ particles are obtained.Among, when the rake angle of the tool is $135^{\circ}$, the tearing depth of the tool reaches the maximum at the end of the workpiece.

(3) Under the conditions of $n=14000 \mathrm{r} / \mathrm{min}, v_{\mathrm{w}}=$ $0.007 \mathrm{~m} / \mathrm{min}$, and grinding depths of $10 \mu \mathrm{m}, 20 \mu \mathrm{m}$, and
$30 \mu \mathrm{m}$ respectively, the $R a$ values are $0.386 \mu \mathrm{m}, 0.591$ $\mu \mathrm{m}$, and $1.073 \mu \mathrm{m}$. As the grinding depth continues to increase, the surface quality continues to decline.

(4) Under the grinding parameters of $n=14000 \mathrm{r} / \mathrm{min}$, $v_{\mathrm{w}}=0.005 \mathrm{~m} / \mathrm{min}$, and $a_{\mathrm{p}}$ of $10 \mu \mathrm{m}, 20 \mu \mathrm{m}$ and $30 \mu \mathrm{m}$, the microstructure of the subsurface layer is detected. When the spindle speed and feed rate are unchanged, the grinding depth is inversely proportional to the quality of the sub-surface layer. As the stress transfer distance increases, the stress transfer effect gradually decreases. Therefore, the farther away from the surface, the better the quality, and the number of voids formed closer to the processed surface will be more. When the stress is not enough to break the $\mathrm{SiC}$ particles, cracks are left in the sub-surface layer of the $\mathrm{SiCp} / \mathrm{Al}$ composite material. The length of the crack is determined by the distance between the particle location and the machined surface. The longer the distance between the two, the shorter the crack, and vice versa. 


\section{Ethics approval and consent to participate}

This research project has been approved by the Ethics Committee of Liaoning University of Technology.

\section{Consent for publication}

that the work described has not been published before; that it is not under consideration for publication elsewhere;

that its publication has been approved by all co-authors, if any;

that its publication has been approved by the responsible authorities at the institution where the work is carried out.

The Author agrees to publication in the Journal indicated below and also to publication of the article in English by Springer in Springer's corresponding English-language journal. The copyright to the English-language article is transferred to Springer effective if and when the article is accepted for publication. The author warrants that his/her contribution is original and that he/she has full power to make this grant. The author signs for and accepts responsibility for releasing this material on behalf of anyand all co-authors. The copyright transfer covers the exclusive right to reproduce and distribute the article, including reprints, translations, photographic reproductions, microform, electronic form or any other reproductions of similar nature. After submission of the agreement signed by the corresponding author, changes of authorship or in the order of the authors listed will not be accepted by Springer. Journal: Silicon, chemical samples Names of All contributing authors: Guangyan Guo, Qi Gao, Quanzhao Wang, and Yuanhe Hu.

\section{Availability of data and materials}

The data used to support the findings of this study are available from the corresponding author upon request.

\section{Competing interests}

The authors have declared that no conflict of interest exists.

\section{Funding}

This work was supported by the National Natural
Science Foundation of China (No.51775100) and the Doctoral Start-up Fund of Liaoning Province (2019-BS-123).

\section{Authors' contributions}

Guo did all the grinding experiments and wrote the papers. Gao guided Guo to revise the paper. Wang made a parameter measurement of the materials used in this experiment. Hu performed regular segmentation of the $\mathrm{SiCp} / \mathrm{Al}$ composites. All authors read and approved the manuscript.

\section{Acknowledgment}

The authors would like to express their gratitude to the reviewers of the manuscript for their valuable suggestions and comments.

\section{Compliance with ethical standards}

Authors state that the research was conducted according to ethical standard.

\section{Disclosure of potential conflicts of interest}

This research does not involve potential conflicts of interest.

\section{Research involving Human Participants and/or Animals}

This research does not involve human participants and animal research.

\section{Informed consent}

I solemnly declare that the paper "Study on Meso-scale Grinding Surface Roughness and Sub-surface Quality of High Volume Fraction SiCp/Al2024 composites" presented by us is the result of our research. This paper does not contain any work published or written by any other individual or group, except for the content specifically noted and cited in the paper. I fully realize that the legal consequences of this statement shall be borne by me.

\section{Reference}

1. Cui Y (2003) High Volume Fraction SiCp/Al Composites Prepared by Pressureless Melt Infiltration: Processing, 
Properties and Applications[J]. Key Engineering Materials, 249:45-48.

2. Zhang Q, Liu D, Chen GQ, Xiu ZY, Wu GH (2009) Performance and application of SiCp/Al composites for electronic packaging[J]. Physical \& Failure Analysis of Integrated Circuits. ipfa. ieee International Sympo, 252-255.

3. Lee HS, Jeon KY, Kim HY, Hong SH (2000) Fabrication process and thermal properties of $\mathrm{SiCp} / \mathrm{Al}$ metal matrix composites for electronic packaging applications[J]. Journal of Materials Science, 35(24):6231-6236.

4. Fan J (2007) Development and Applications of $\mathrm{SiCp} / \mathrm{Al}$ Composites in Aerospace Field[J]. Materials Review, 21(10):98-101.

5. Shi F, Qian DF, Zhang ZP (2004) Application of SiCp/Al Composite and Its Fabrication by Pressureless Infiltration Technique[J]. Bulletin of the Chinese Ceramic Society, (02):60-65.

6. Yin GQ, Wang D, Cheng J (2019) Experimental investigation on micro-grinding of $\mathrm{SiCp} / \mathrm{Al}$ metal matrix composites[J]. The International Journal of Advanced Manufacturing Technology, (64):66-78.

7. Sun Y, Su ZP, Gong YD, Ba D, Yin GQ, Zhang H, Zhou LH (2021) Analytical and experimental study on micro-grinding surface-generated mechanism of DD5 single-crystal superalloy using micro-diamond pencil grinding tool[J]. Archives of Civil and Mechanical Engineering, 21(1):1-22.

8. Zhou YG, Gong YD, Cai M, Zhu ZX, Gao Qi, Wen XL (2017) Study on surface quality and subsurface recrystallization of nickel-based single-crystal superalloy in micro-grinding $[\mathrm{J}]$. The International Journal of Advanced Manufacturing Technology, 90(5-8).

9. Zheng W, Liu L, Zhang Q, Zhao JS, Cui GX, Wang Q (2019) Simulation of formation mechanism of machined surface defects in ultrasonic grinding of $\mathrm{SiCp} / \mathrm{Al}$ composites[J]. Journal of Solid Rocket Technology,42(06):793-800.

10. Zhang CY, Sun Y, Zhao LG (2013) Simulation of single diamond abrasive particle grinding $\mathrm{SiCp} / \mathrm{Al}$ composites[J]. Tool Engineering, 47(11):15-19.

11. Ma ZF, Liang GX, Zhang H, Tian JJ (2019) Simulation and experimental investigation of high-speed grinding Ti6Al4V with single grain[J]. Tool Engineering,, 53(04):49-53.

12. Wang T, Xie L, Wang X (2015) Simulation study on defect formation mechanism of the machined surface in milling of high volume fraction $\mathrm{SiCp} / \mathrm{Al}$ composite[J]. The
International Journal of Advanced Manufacturing Technology, 79(5-8):1185-1194.

13. Yu X L (2012) Research on precision grinding mechanism and surface evaluation of $\mathrm{SiCp} / \mathrm{Al}$ composites with high volume fraction[D]. Shenyang University of Technology.

14. Guan JL, Zhu L, Chen L, Ma XQ, Zhang XH (2014) Research on ELID Grinding Efficient Surface Forming Mechanism of SiCp/Al Composites[J]. Advanced Materials Research, 1027:107-110.

15. Wei X, Chen GD, Wang B, Chen GH, Yang L, Tang WM (2021) Characteristics and grinding performance evaluation of the high-fraction GNFs/SiCp/6061Al matrix hybrid composites[J]. Journal of Alloys and Compounds, (29):159049.

16. Sun W, Duan CZ, Yin WD (2021) Chip formation mechanism in machining of $\mathrm{Al} / \mathrm{SiCp}$ composites based on analysis of particle damage[J]. Journal of Manufacturing Processes, 64:861-877.

17. Huang ST, Zhou L, Yu XL, Xiu LF (2012) Study of the mechanism of ductile-regime grinding of $\mathrm{SiCp} / \mathrm{Al}$ composites using finite element simulation[J]. International Journal of Materials Research (formerly Zeitschrift fuer Metallkunde), 103(10):1210-1217.

18. Gu P, Zhu CM, Tao Z, Yu YQ (2021) A grinding force prediction model for $\mathrm{SiCp} / \mathrm{Al}$ composite based on single-abrasive-grain grinding[J]. International Journal of Advanced Manufacturing Technology, 109(5-8).

19. Du JG, Ming WY, Cao Y, Ma J, He WB, Li XK (2019) Particle Removal Mechanism of High Volume Fraction SiCp/Al Composites by Single Diamond Grit Tool[J]. Journal of Wuhan University of Technology-Mater Sci Ed, 34(002):324-331.

20. Zhang FL, Li MC, Wang J, Huang HP, Wang CY, Zhou YM (2020) Effect of arraying parameters on dry grinding performance of patterned monolayer brazed $\mathrm{CBN}$ wheel[J]. The International Journal of Advanced Manufacturing Technology, 107(5):2081-2089.

21. Wang YS, Xiu SC, Dong L, Sun C (2016) Study on strengthened layer of workpiece in prestress dry grinding[J]. The International Journal of Advanced Manufacturing Technology, 90(5-8).

22. Qu MN , Jin T, Xie GZ, Cai R, Yi J, Lu AG (2019) Thermal damage control for dry grinding of $\mathrm{MgO} / \mathrm{CeO} 2$ glass ceramic[J]. International Journal of Advanced Manufacturing Technology, 105(7-8). 
23. Johnson GR, Cook WH (1985) Fracture characteristic of three metals subjected to various strains: strains rates, temperature and pressure $[\mathrm{J}]$. Engineering Fracture Mechanics.21(1):31-48.

24. Akbari M, Buhl S, Leinenbach C, Wegener K (2016) A new value for Johnson Cook damage limit criterion in machining with large negative rake angle as basis for understanding of grinding $[\mathrm{J}]$. Journal Materials Processing Technology, 234:58-71. 